\title{
Implementing farm-level environmental sustainability in environmental performance indicators: a combined global- local approach
}

Nina Repar*, Pierrick Jan, Dunja Dux, Thomas Nemecek, Reiner Doluschitz

N. Repar, P. Jan, D. Dux

Farm Economics Research Group

Agroscope, Institute for Sustainability Sciences ISS

Tänikon 1, 8356 Ettenhausen, Switzerland

*Corresponding author. E-mail: nina.repar@agroscope.admin.ch

Telephone: +41584803146

Fax: +41523651190

\section{N. Repar, R. Doluschitz}

Computer Applications and Business Management in Agriculture, Institute of Farm Management

University of Hohenheim

Schloß, Osthof-Süd, 70593 Stuttgart, Germany

\section{T. Nemecek}

Life Cycle Assessment Research Group

Agroscope, Institute for Sustainability Sciences ISS

Reckenholzstrasse 191, 8046 Zurich, Switzerland

\section{Abstract}

As major generators of environmental impacts, farms play a crucial role in enhancing the environmental sustainability of food-supply chains. However, appropriately assessing farm environmental performance poses a challenge; a plethora of different indicators have been used for this purpose, sometimes in the absence of conceptual considerations. This paper develops a broadly implementable framework for defining and measuring farm environmental performance which complies with the environmental sustainability concept viewed from an ecological perspective. After providing a critical review of existing indicators in the literature for measuring farm environmental performance and identifying their strengths and above all their weaknesses, it proceeds to develop ideas on how to implement the environmental sustainability concept at farm level. Starting at the macro level, these ideas are based on the central concept of ecosystem carrying capacity (constraints) referring to biophysical threshold thinking. The implementation of this concept at farm level results in the framework that we propose for measuring farm environmental performance. Environmental sustainability requires compliance with the carryingcapacity constraints imposed by the natural ecosystem within which a farm operates. Compliance with carrying capacity must occur at both local and global ecosystem 
levels, requiring a distinction between local and global farm environmental performance. The global environmental performance of a farm is defined as its relative contribution to compliance with the carrying capacity of the global ecosystem, and is measured by means of an indicator of environmental intensity over the entire production chain up to the farm gate. The local carrying-capacity constraint can be understood as the maximum environmental impact per unit of farmland area that can be sustained by the local ecosystem. Local environmental performance is therefore measured by means of an area-based indicator. Whereas all environmental issues must be considered at a global level, for some of them local level consideration is also required. Implementing separate local and global environmental performance indicators, as opposed to using only global or local indicators without distinguishing between them in conceptual terms, provides a more appropriate assessment of the environmental performance of farms, as well as a better basis for comparison between farms. Furthermore, it eliminates the risk of shifting environmental problems from the local to the global scale or vice-versa. The framework highlights the complexity of the environmental sustainability concept, which cannot be reduced to a single "one size fits all" indicator.

\section{Keywords}

Agriculture

Environmental sustainability

Carrying capacity

Farm environmental performance

Life cycle assessment (LCA)

\section{Introduction and objectives}

Agricultural activity has always shared a close bond with the surrounding natural ecosystem as a result of the complex network of interactions occurring between this human activity (technosphere) and the natural environment in which it operates (biosphere) (Schau and Fet, 2008). These interactions have allowed agriculture to use many natural ecosystem services in its production processes (Zhang et al., 2007). At the same time, agriculture has generated negative environmental externalities influencing the health and wellbeing of the ecosystem that provides these vital services (Dale and Polasky, 2007; Power, 2010). The list of these externalities is long, and includes greenhouse-gas emissions, pollution due to 
nutrient run-off, water shortages, soil degradation, loss of biodiversity, and disruption of aquatic ecosystems (Godfray et al., 2010).

Nowadays, the link between agriculture and the ecosystem is of increasing concern, given that "green revolution" technologies and the associated decades of agricultural intensification, which have succeeded in increasing food production, have also caused extensive environmental damage at the local, regional and global levels of the Earth ecosystem (Matson et al., 1997; Vitousek et al., 1997; Foley et al., 2005). Humanity has reached the point where "its rapidly growing reliance on fossil fuels and industrialized forms of agriculture could damage the systems" that have kept the Earth in the state suitable for the development of human life, as it may be approaching planetary boundaries for global freshwater use, change in land use, ocean acidification, and interference with the global phosphorus cycle, whereas climate change, biodiversity loss, and nitrogen cycles have already exceeded these boundaries (Rockström et al., 2009). At the same time, at a global level, rising populations and the economic growth of developing countries are leading to a major increase in the demand for food and to changes in food consumption patterns marked by an increase in the proportion of fats and animal proteins in the human diet (Gerbens-Leenes et al., 2010; Godfray et al., 2010). This in turn calls for further increases in agricultural production, putting even greater pressure on scarce natural resources (Gerbens-Leenes et al., 2010). These global trends underscore the importance and urgency of effectively addressing environmental issues in agri-food systems, and demand further exploration of innovative solutions and approaches for successfully dealing with the problems in question.

There are several reasons why farms play such an important role in creating sustainable food chains. First of all, farms are the place where day-to-day decisions regarding the use of economic and environmental resources are made. Taken as a whole, these decisions result in the production of agricultural commodities and services, but also cause negative environmental externalities. Owing to the particular role played in the agricultural production process by land, environmental resource use in agriculture is in many respects highly specific.

Secondly, once we recognise the role of farms as major environmental impact generators in the food chain, their importance in achieving sustainable food chains becomes even more evident. For the environmental impacts related to nutrient management, toxicity, phosphorus, and land use in particular, the cradle-to-farm-gate 
link is responsible for a large share of the impacts generated over the entire food supply chain (e.g. Eide, 2002, Hospido et al., 2003, Gerber et al., 2010, Thoma et al., 2013, Bystricky et al., 2014 for the dairy chain; Korsaeth et al., 2012, Bystricky et al., 2014, Kulak et al., 2014 for the bread supply chain). The monitoring, assessment and enhancement of farm environmental performance is therefore an issue of the utmost importance for improving the environmental sustainability of the entire food chain. Environmental performance is generally defined here as the ability of a farm to comply with the biophysical restrictions (in terms of the use of natural resources and generation of polluting emissions) imposed by the natural ecosystem in which it operates to ensure the short- and long-term provision of the support, regulatory and provisioning services rendered by said natural ecosystem to humanity.

In scientific practice, a plethora of different indicators have been used to measure environmental performance at farm level. In many studies, the definition of these environmental indicators is mainly driven by considerations regarding data availability or data-collection feasibility, without conceptually considering which indicators are actually required for the assessment of farm environmental performance. An absence of conceptual considerations behind the indicators may result in the questionable relevance and usefulness of the indicators thus obtained.

To ensure truly sustainable development in the agri-food sector, it is essential for farm environmental performance indicators to be consistent with the meaning and principles of the sustainability concept originally derived from the macro level. Such indicators aim to compare farms in terms of their relative contribution to environmental sustainability, and ultimately to improve environmental performance. Taking the macro-level environmental sustainability concept as its point of departure, this paper therefore aims (i) to develop ideas on how to implement the environmental sustainability concept at farm level, and (ii) to build on these ideas in order to propose a sound framework for defining and measuring environmental performance at farm level.

Our research makes a threefold contribution to the discussion on farm environmental performance assessment. Firstly, our work focuses exclusively on defining and measuring environmental performance at farm (i.e. micro-) level. Secondly, the development of environmental performance indicators starts with and is based on consideration of the importance and implications of the macro-level environmental sustainability concept for the definition and measurement of environmental performance at farm level, which to the best of our knowledge is the main 
uniqueness of our work. The development of indicators is thus rooted in a more general context ensuring that the developed indicators are consistent with the macrolevel environmental sustainability concept as viewed from an ecological perspective. Thirdly, our considerations attempt to reconcile different perspectives, namely the macro- vs. the micro-perspective, and the economists' vs. the scientists' view.

The present paper is organised as follows: Section 2 provides a literature review of the typologies of indicators designed to measure farm-level environmental performance. This section does not purport to provide an exhaustive, in-depth review of all existing indicators. Rather, its main general objective is to classify the existing range of indicators into different types and - based on selected examples of types of farm environmental performance indicators - to show how limited some indicators may be, and why it is essential to consider the meaning behind farm environmental performance if we wish to move towards greater sustainability in agricultural production. Section 3 deals with the theoretical underpinnings of our work, focusing on the concepts of environmental sustainability and carrying capacity. The aim of this section is to provide a sound basis for implementing the macro-level environmental sustainability concept in farm environmental performance indicators. In Section 4, we propose the framework for defining and measuring environmental performance at farm level, followed by a discussion in Section 5 and conclusions in Section 6 .

\section{Measuring environmental performance at farm level: a literature-based review of the existing types of indicators and approaches used in the assessment of farm environmental performance}

A review and analysis of the literature reveals a wide variety of indicators that have been used to measure environmental performance at farm level. This section aims to classify the range of indicators found in the literature, to discuss the main types of indicators, and to draw initial conclusions regarding their suitability for assessing farm environmental performance.

Defining a farm environmental performance indicator involves two steps: (i) the choice of the variable to be used to assess the environmental impact of the investigated farming system (said variable being hereafter also referred to as the "environmental indicator"); and (ii) the definition of the environmental performance indicator (hereafter also referred to as the "performance indicator"), which is based on the environmental variable of the first step. 
In a first subsection, we present different typologies found in the literature for classifying the different types of variables used to assess the environmental impact of a farming system. The strengths and weaknesses of the main types of environmental indicator are then discussed. In a second subsection, we describe the three main streams of approach for defining the performance indicator, followed by a critical review of these three streams of approach. The last subsection summarises the lessons to be learned from this review.

2.1 Typologies of existing farm-level environmental indicators and related terminologies

The present subsection is primarily based on van der Werf and Petit (2002), Schröder et al. (2003), and Payraudeau and van der Werf (2005), who propose typologies of different possible variables that can be used to assess the environmental impact of farming systems. These variables are indicators which are alternative or indirect measures that provide information on the farming system's impact on the environment in terms of the issue of concern (van der Werf and Petit, 2002; Payraudeau and van der Werf, 2005). The use of environmental indicators is motivated by the difficulty of making direct measurements owing to e.g. methodological problems or practical reasons of cost and time (Bockstaller and Girardin, 2003).

\subsubsection{Indicator position in the environmental impact pathway}

In their review of methods for the environmental impact assessment for a farming region, Payraudeau and van der Werf (2005) distinguish between four environmental indicator classifications (and associated terminologies) depending on the part of the cause-effect chain, also called impact pathway (linking the agricultural production practices to environmental impact), covered by the classification and on the position of the indicators in this chain. These are (i) pressure and state indicators, (ii) meansbased and effect-based indicators, (iii) emission and impact indicators, and (iv) midpoint and endpoint indicators. As is obvious from Payraudeau and van der Werf (2005), indicator classifications i-iv are not mutually exclusive, but rather interconnected.

There is a trade-off between the feasibility and environmental relevance (i.e. the effectiveness of the environmental assessment) of environmental indicators (Payraudeau and van der Werf, 2005). Basically, indicators at the beginning of the 
cause-effect chain (e.g. the nitrogen fertiliser applied) are easier to quantify than indicators at the end of this chain (e.g. potential disappeared fraction of species due to eutrophication). However, the indicators at the beginning of the chain are poorly related to the environmental objective and thus do not allow an actual evaluation of the environmental effect of farming practices (van der Werf and Petit, 2002). On the other hand, end-chain indicators have a higher relevance in environmental terms than those at the beginning of the chain, because they are much closer to showing the actual influence on the state of the environment (Payraudeau and van der Werf, 2005). Nevertheless, the assessment of end-chain indicators remains a highly challenging undertaking. The assessment of environmental impacts often requires a very comprehensive data collection and highly complex impact-assessment models, which in turn increases the costs and uncertainty of the assessment, often leading in practice to the use of means-based indicators that are easier to measure (Bare et al., 2000; van der Werf and Petit, 2002; Jolliet et al., 2004; Payraudeau and van der Werf, 2005).

Considerations in the literature confirm that preference should be given to indicators at the end of the cause-effect chain (van der Werf and Petit, 2002; Payraudeau and van der Werf, 2005) or, if this is not possible, to indicators with an intermediate position on the means- and effects-based spectrum. The use of means-based indicators is not recommendable because evaluations based on this type of indicators "will not contribute to recognising errors and improving practices" (van der Werf and Petit, 2002).

Whether midpoint or endpoint impact indicators are to be preferred is a question that has been discussed in the life cycle assessment (LCA) literature (e.g. Bare et al., 2000; Payraudeau and van der Werf, 2005). Due to the complexity and uncertainties associated with endpoint modelling (Jolliet et al., 2004), the use of midpoint indicators is often deemed to be a more pragmatic solution offering the best compromise between environmental relevance and indicator accuracy (Bare et al., 2000; Payraudeau and van der Werf, 2005).

\subsubsection{Spatial system boundaries of the environmental assessment}

Environmental indicators differ not only in terms of their position in the cause-effect chain, but also with respect to the spatial system boundaries of the underlying environmental assessment, i.e. to the part (links) of the food (or value) chain covered by this assessment. Whereas conventional, non-LCA-based farm environmental assessments cover just the farm itself ("on-farm assessment"), LCA-based farm 
environmental performance assessments adopt a production-chain perspective, and hence encompass both on-farm and off-farm links (upstream stages) of the production chain. LCA is a methodological framework for assessing the environmental impacts of a product throughout its whole life cycle (i.e. from "cradle to grave") (Rebitzer et al., 2004). Despite this, most LCA applications conducted at whole-farm level which aim to assess farm environmental performance do not cover the entire life cycle of the products, but focus on the cradle-to-farm-gate link of the food chain. This exclusion of the farm-gate-to-grave link is explained by the fact that the farmer has very little (if any) influence on what happens in the downstream stages (processing, retail, and consumption) of the food chain. The focus on the cradle-to-farm-gate link assumes that the nature of the activities occurring at farm level is homogeneous among the farms investigated, and, above all, that no processing or any other downstream-stage activities occur at farm level, or - if they do - that they should be excluded from the LCIA. This cradle-to-farm-gate-chain perspective prevents the shifting of any environmental impacts from the on-farm to the upstream stage of the agricultural production process, and is therefore preferable to an assessment that focuses exclusively on the on-farm level.

2.2 Moving from environmental variables to farm-level performance indicators: three main groups of approaches

Once the environmental indicator is defined and assessed, the second step of any farm environmental performance assessment is to define the performance indicator deriving from the environmental indicator that will enable a comparative judgement of farms in terms of their compliance with the environmental sustainability objectives. This section reviews the three main groups of approaches to defining the environmental performance indicator that are found in the literature.

\subsubsection{Productive-efficiency-based approaches}

Agricultural economists from the productive efficiency field have generally followed one of four different types of approaches for assessing environmental performance at micro-level. The first stream of approach, labelled environmentally adjusted

production efficiency (EAPE) by Lauwers (2009), involves integrating environmental issues - especially the undesirable environmental output - into traditional approaches to assessing (economic) productive efficiency, and "treating the environment as merely one criterion among others in a technically oriented 
efficiency assessment" (Kuosmanen and Kortelainen, 2005). As emphasised by Lauwers (2009), the manner in which the undesirable outputs are included in the model (i.e. the specification of the model used to measure efficiency) influences not only the results but also their interpretation. For example, Reinhard et al. (1999) define environmental efficiency as the "ratio of minimum feasible to observed use of an environmentally detrimental input [nitrogen surplus], conditional on observed levels of the desirable output [monetary farm output] and the conventional inputs [conventional economic inputs: labour, capital, and variable inputs]'.

Over the past decade, alternative productive-efficiency-based approaches have been proposed to measure environmental performance. One of these alternative approaches tackles the issue from the perspective of ecological economics or industrial ecology. Instead of including environmental issues in conventional models for measuring productive efficiency, this alternative approach, also referred to by Lauwers (2009) as the frontier eco-efficiency (FEE) model, assesses ecoefficiency separately by considering the economic outcome as an output and the environmental outcome (e.g. emissions or environmental impacts) as an input in the production model (Lauwers, 2009).

Coelli et al. (2007) and Hoang and Coelli (2011) have shown that a number of the EAPE models mentioned previously are inconsistent with the materials balance condition, also referred to by Lauwers (2009) as the materials balance principle (MBP). Also known as the first law of thermodynamics or law of conservation of mass/energy (Hoang and Rao, 2010) and applicable to all materials (such as nutrients) and energy flows, this principle is "an essential biophysical condition stating that flows from and into the environment are equal' (Lauwers, 2009). To overcome the MBP inconsistency problem of EAPE methods, Coelli et al. (2007) propose an approach that treats the nutrient content of inputs and outputs in the same way as input and output prices are treated in cost-, revenue-, or profitefficiency assessments. Termed the MBP-adjusted approach by Lauwers (2009), this third stream of approach can be implemented for all nutrients (e.g. nitrogen, phosphorus). The environmental efficiency of a farm - defined as "the ratio of minimum nutrients over observed nutrients" (Coelli et al., 2007) - can be broken down into its two component parts, namely technical efficiency and environmental allocative efficiency.

Hoang and Rao (2010) argue that environmental efficiency measures based on the MBP-adjusted approach are faced with two main limitations. The first is the 
ambiguous treatment of non-material inputs such as labour, capital, and services, for which no universally accepted weights (materials content) are available (Hoang and Rao, 2010). The second limitation derives from the problem of choosing weights when more than one material is involved in the production process (Hoang and Rao, 2010; Hoang and Alauddin, 2012).

These two limitations can be overcome by making use of the cumulative exergy balance instead of the material balance (Hoang and Rao, 2010). The cumulative exergy balance is calculated as the difference between the cumulative exergy in inputs and exergy in outputs (Hoang and Rao, 2010; Hoang and Alauddin, 2012) and thus implies the adoption of an LCA perspective. The cumulative exergy balance is incorporated into frontier-based methods for the assessment of environmental performance in much the same manner as the materials balance. The sustainable efficiency derived from the cumulative exergy balance (CEB) approach is defined "as the ratio of feasible minimum total amount of cumulative exergy to the aggregate cumulative exergy in the observed input vector" (Hoang and Rao, 2010), and can be broken down into the components of technical efficiency and exergy allocative efficiency (Hoang and Rao, 2010).

As outlined by Hoang and Alauddin (2012), the CEB approach does not render the MBP-adjusted approach redundant. Whereas the CEB approach is better suited to capturing the aggregate effects of cumulative resources use and pollution, the MBPadjusted approach is particularly suitable for the analysis of more-specific types of pollution, provided that a proper science-based quantification of the weights of various materials is possible (Hoang and Alauddin, 2012).

\subsubsection{LCA-based approaches}

In an LCA-based approach, the environmental performance indicator is defined via the definition/choice of functional unit (FU) that occurs according to ISO (2006) in the "goal and scope definition" phase of an LCA. Environmental performance is expressed as the amount of environmental impacts generated per FU. Each agricultural system investigated fulfils one or more functions. The FU quantifies the function of a product system (adapted from ISO, 2006) or, put differently, assesses the services provided by the system investigated in terms of the function under consideration. For example, the function of providing food by delivering energy to the human body can be quantified using the FU "digestible energy output". The environmental performance of a farm is quantified by relating the environmental impact of the farm to the FU in question. The choice of FU is highly dependent on the 
aim of the investigation (de Boer, 2003; Schau and Fet, 2008; Hokazono and Hayashi, 2015; van der Werf and Salou, 2015). Basically, three main groups of FUs can be distinguished: product-based, area-based, and financial FUs. The classification proposed below is derived from the considerations of Nemecek et al. (2008), Schau and Fet (2008), and van der Werf et al. (2014), supplemented by a literature review of the FUs used in farm-level LCAs. The product-based FUs refer to the productive function of agriculture (the production of food, feed, and biomass), and include (i) mass or volume FUs, (ii) nutritional FUs quantifying the nutritional value (e.g. energy or protein content) of the food produced, and (iii) monetary FUs reflecting the monetary value of the food, or more generally, outputs, produced. The area-based FUs (i.e. the surface area of the land used) relate to the land-use/landoccupation function of agriculture, while the financial FUs refer to the function of farm income/profit generation, and include FUs such as farm gross margin and farm net income.

Farm-level LCA applications found in the literature either use one FU only (mainly product-based, viz., mass, volume, or energy FUs - e.g. Cederberg and Mattsson, 2000; Casey and Holden, 2005; Casey and Holden, 2006; Thomassen et al., 2008; Mu et al., 2014) or multiple FUs. In the latter case, either product-based and areabased FUs are both applied for all impact categories (e.g. Basset-Mens and van der Werf, 2005; Hokazono and Hayashi, 2015), or, in some investigations, product-based FUs are applied for all impact categories combined with area-based FUs for selected impact categories (such as eutrophication and acidification - e.g. de Boer, 2003; Thomassen et al., 2009). A few applications also implement three types of FUs for all impact categories considered, (e.g. van der Werf et al., 2009; van der Werf and Salou, 2015).

The choice of FU is particularly crucial when comparing products in the agricultural sector, since the results of the comparison of farming systems (e.g. intensive vs. organic farming) will vary substantially depending on the FU chosen (see for instance Halberg et al., 2005; van der Werf and Salou, 2015).

\subsubsection{Approaches outside the LCA and productive-efficiency field}

To create a farm environmental performance indicator, most environmental scientists foreign to the LCA field as well as agricultural economists outside of the productiveefficiency field take a somewhat similar approach to that of environmental scientists from the LCA field. The performance indicator is also expressed as the ratio between the environmental indicator and a specific FU (e.g. ha of land area). The 
environmental variables used are either means-based (e.g. nitrogen fertiliser applied) or or have an intermediate position on the means- and effect-based spectrum (e.g. nitrogen surplus). The two most common groups of FUs are the product-based ones (e.g. kg of output; cf. e.g. Nevens et al., 2006; Beukes et al., 2012) and the areabased ones (land area, e.g. Oenema and Pietrzak, 2002; Nielsen and Kristensen, 2005; Groot et al., 2006; Nevens et al., 2006; Jan et al., 2015; Micha and Heanue, 2015). Detailed examples of such indicators can be found in van der Werf and Petit (2002), Schröder et al. (2003), and Halberg et al. (2005b).

\subsection{Critical review of existing farm-level environmental performance indicators}

This subsection provides a critical review of the three main groups of approaches for defining and measuring farm environmental performance presented in Section 2.2, with a special focus on (i) the productive efficiency measures adapted for use as environmental-performance measurement tools, and (ii) the discussion of FUs from an LCA perspective.

2.3.1 Approaches from the productive efficiency field: moving from approach-driven to problem-driven

The first type of approach (EAPE models) proposed in the productive-efficiency field to assess environmental performance at micro-level was more approach-driven than problem-driven. Essentially, the question originally addressed during development of the EAPE models was not how to define environmental performance at micro-level in a manner consistent with the (biophysical) environmental sustainability concept, but rather how to incorporate environmental issues in the existing approaches or, put differently, how to accommodate the existing models to take into account environmental pollutants or, more generally, environmental "bads". With the emergence of the FEE approach, and later, of the MBP-adjusted and CEB approaches, environmental performance development became less approach- and more problem-oriented. Basic biophysical laws underlying ecosystem functioning, and hence a more biophysical concept of environmental sustainability, gradually came to the fore. Despite this new and highly valuable perspective, a thorough consideration of how to implement the environmental sustainability concept at farm level - or, more generally, at micro-level - in environmental performance indicators is still absent. This may be because the primary focus of work done in this field is still the methodological development of productive-efficiency measurement tools. 


\subsection{2 "Functional units" approach from the LCA field}

The FU-based approach used in the LCA field is - compared with the approaches coming from the productive efficiency field - less methodologically driven and more focused on the issue of environmental sustainability. Even so, farm-level applications of this approach also suffer from shortcomings. Firstly, some performance indicators originating in this field suffer from a system-boundaries inconsistency between the environmental impact variable and the chosen FU. This is seen to be the case when we analyse the environmental performance in terms of its landscape maintenance ${ }^{1}$ function. The performance indicator created for this purpose relates the environmental impacts generated throughout the entire chain up to the farm gate to the farm's usable agricultural area, the latter representing only the on-farm part of the production chain. The estimated cradle-to-farm-gate environmental impacts are however also very often associated with landscape maintenance in the off-farm upstream stages of the life cycle ${ }^{2}$. This off-farm landscape maintenance is not taken into account in the on-farm area. From a life-cycle perspective, in order to keep the spatial system boundaries consistent, the off-farm landscape maintenance (i.e. the corresponding off-farm area) associated with the activity of the farm investigated should also be included in the area-based environmental performance indicator. The particular treatment of landscape maintenance results from the non-market good/positive externality nature of this output. This example shows how important it is to keep the spatial boundaries of the system clearly defined and consistent when creating the performance indicator.

Secondly, the use of monetary FUs in LCA environmental performance indicators is highly problematic; because prices are very often biased and do not reflect the real scarcity of goods and resources, the use of monetary FUs may yield biased environmental performance indicators. However, assuming perfectly competitive and efficient markets, and hence unbiased prices, monetary FUs possess two decisive advantages. Firstly, prices enable the aggregation of different biophysical outputs expressed in the same or different units to a single monetary output. Secondly, the monetary FU (also referred to as the "economic value FU") is able to take account of

\footnotetext{
1 "Landscape maintenance" is used here as a generic term for the function of land use, or more precisely, for the maintenance of a cultivated/open landscape.

${ }^{2}$ This is e.g. the case when the farm investigated purchases forage (such as hay) from another farm.
} 
the quality of a product based on the latter's price (van der Werf and Salou, 2015). This second advantage, however, is not supported by empirical evidence. Several studies have in fact shown that price and quality are only weakly correlated, especially in the food and beverages sector, "making price a poor signal to infer quality from" (Kirchler et al., 2010). In the German food sector, the price-quality correlation has even been found to be negative (Schulze et al., 2008).

Thirdly, and more generally, the choice of FU(s) for deriving the environmental performance indicator(s) should stem from consideration of the significance of the farm environmental performance concept, and not, as is the case in several contributions, from a simple consideration of all functions that agriculture can potentially fulfil. We would argue that when defining FUs for the purpose of measuring environmental performance, the focus should be on the primary functions of agriculture from a biophysical environmental perspective, viz., the production of food, feed, and biomass, as well as land use. The financial function is not one of agriculture's main biophysical environmental functions, and is therefore not of interest in an environmental performance assessment.

We are aware that monetary FUs associated with the financial function are used with the aim of obtaining a sort of "all-in-one" combined economic/environmental performance indicator. This demonstrates that the performance indicators derived from the LCA-based FU approach follow one of two different (conceptual) objectives - to measure environmental performance, or to assess combined environmental/economic performance. It is unlikely that all LCA practitioners are aware of this (conceptual) distinction, which might make the correct interpretation of the indicators difficult.

\subsubsection{Approaches outside of the LCA and productive-efficiency field}

Because this approach category does not apply a life-cycle perspective to the process of quantifying environmental performance, it risks shifting environmental problems from one part of the life cycle to another. To give an example, if a dairy farm that depends heavily on concentrates and whose production generates environmental impacts in the upstream stages has performance indicators that focus on on-farm impacts, the existence of these upstream impacts will be ignored, causing the farm's environmental performance to appear better than it actually is, owing to the shifting of the environmental problems from the farm to the upstream stages. 
Furthermore, a boundary problem may occur if the environmental variable is associated with an FU taking into account the cradle-to-farm-gate link of the life cycle (as is the case with most product-related FUs). Moreover, the use of performance indicators that rely on means-based environmental variables can be contested for the reasons set out in Section 2.1. Last but not least, just as with any other environmental performance assessment, the use of monetary FUs is deemed inappropriate in this context as well.

\subsection{Summary of the lessons learned}

The aim of this review was not to provide an exhaustive examination of all existing indicators for measuring environmental performance at farm level, but rather to furnish a systematic overview of the main types of farm environmental performance indicators found in the literature together with a number of critical considerations, and to discuss the strengths and weaknesses of these indicators.

The review clearly highlights the existence of numerous approaches or indicators used to measure farm environmental performance, to a large extent owing to the different academic backgrounds of these publications (i.e. natural sciences as opposed to agricultural economics). Whereas natural scientists seem to focus more on a wide range of individual performance indicators when assessing environmental performance, agricultural economists tend to refine existing approaches from the sphere of productive (economic) efficiency measurement for use as environmental performance measurement tools.

Furthermore, the review shows that existing approaches vary greatly in terms of (i) the environmental indicator's position in the environmental impact pathway, (ii) spatial boundaries of the system underlying the environmental assessment, and (iii) definition of the performance indicator.

Although explicit definitions of farm environmental performance are rarely found in the literature, an implicit definition can be derived primarily from the type of variable(s) chosen to represent environmental performance. The different groups of approaches for determining environmental performance reflect different understandings of the concept, shaped primarily by the outlook of the scientific field in question. Ideally, however, the definition of environmental sustainability should not depend on the researcher's discipline. 
Several problems relating to the assessment of farm environmental performance addressed in this review indirectly highlight the lack of attention paid to the implementation of the environmental sustainability concept at farm level. This might result in indicators that are not appropriate for decision-making. The following section therefore explores the theoretical foundations on which the farm environmental performance concept must be based if meaningful measures and definitions are to be developed.

\section{Theoretical underpinnings: from environmental sustainability to farm environmental performance}

Starting from the macro-level (environmental) sustainability concept, the aim of this section is to develop ideas on how (and how not) to implement this concept in farm(i.e. micro-) level environmental performance indicators.

\subsection{Environmental sustainability: a biophysical concept}

Sustainable development and concepts relating to sustainability were widely popularised by the report "Our Common Future", published in 1987 by the World Commission on Environment and Development (WCED). In this report, sustainable development is basically defined as development "that meets the needs of the present without compromising the ability of the future generations to meet their own needs" (WCED, 1987). The approach to sustainability advocated by the WCED (1987) has been criticised on various accounts, ranging from the scientific appropriateness of the concept of human-needs satisfaction (Károly, 2011), to the very idea of limitless growth (Goodland, 1995), to its non-consideration of the ecological (biophysical) carrying-capacity constraint of the Earth's ecosystem(s) (Rees, 1996). A focus on the ecological perspective of the ecological (biophysical) carrying-capacity constraint considered here creates a general definition of environmental sustainability similar to the WCED's oft-quoted definition of sustainable development, but which adds the crucial component of ecosystem health - namely, "meeting the resource and services needs of current and future generations without compromising the health of the ecosystems that provide them" (Morelli, 2011). More precisely, environmental sustainability can be defined as a "condition of balance, resilience, and interconnectedness that allows human society to satisfy its needs while neither exceeding the capacity of its supporting ecosystems 
to continue to regenerate the services necessary to meet those needs nor by our actions diminishing biological diversity" (Morelli, 2011). Similarly, Goodland (1995) defines the ultimate goal of environmental sustainability as the perpetual maintenance of global life-support systems through sustaining the environmental sink and source capacities. He considers environmental sustainability to be composed of a set of constraints on the four major activities in the human economic subsystem: the use of renewable and non-renewable resources on the source side, and pollution- and waste assimilation on the sink side.

Owing to the complexity of the issue, measuring environmental sustainability remains a challenging problem. Monetary evaluations in particular are fraught with serious difficulties owing to the biased nature of price information, which in turn stems from the fact that prices very often fail to reflect the real scarcity of goods and resources, since "standard monetary analyses are blind to ecological structure and function and are therefore incapable of indicating either ecologically meaningful scarcity or incipient systems destabilization" (Rees, 1996). Evidence suggests that in the case of natural resources, prices are often far from reflecting true scarcities, due to the occurrence of market failures (Cabeza Gutés, 1996; Farley, 2008; Turner and Daily, 2008) such as the inability of market-price formation to take into account future scarcities (Browne, 2012) and, above all, to integrate the demand of future generations (Bromley, 1989). For this reason, the use of "environmentally myopic market signals" when performing biophysical evaluations (Pelletier and Tyedmers, 2011 ) is strongly discouraged. It is important to bear in mind that environmental sustainability is a natural-science concept governed by biophysical laws that cannot be ignored (Goodland, 1995). In choosing the indicators for environmental evaluations or performance assessments, therefore, biophysical indicators should take precedence over monetary indicators.

In agriculture, biophysical variables are associated with the primary functions of agriculture as viewed from a biophysical environmental perspective, namely the production of food, feed, and biomass, and in some cases land use.

3.2 Carrying-capacity compliance as a precondition for environmental sustainability

Environmental sustainability requires humanity to remain within the biophysical carrying capacity of the planet (Robinson, 2004). More precisely, this straightforward precondition for environmental sustainability means that "human population and 
activity should not surpass the carrying capacity of the biosphere, its renewing, resource, and sink capacities" (Károly, 2011), or, in other words, "sustainability depends on the size and spatiotemporal characteristics of humanity's footprint relative to Earth's carrying capacity" (Hoekstra and Wiedmann, 2014). As with Lowe and Evans (1995), the concept of ecosystem carrying capacity is central to our conceptual considerations with respect to the implementation of the environmental sustainability concept at farm level. Carrying capacity is understood as the "maximum load that can be safely imposed on the environment by people", or more precisely, as the "maximum rates of resource harvesting and waste generation (the maximum load) that can be sustained indefinitely without progressively impairing the productivity and functional integrity of relevant ecosystems wherever the latter may be located" (Rees, 1996). This carrying capacity is closely related to the input-output rule for environmental sustainability (e.g. keep wastes within assimilative capacities, harvest within regenerative capacities of renewable resources, deplete nonrenewable ones at the rate at which renewable substitutes are developed) proposed by Goodland and Daly (1996). Carrying capacity refers to area-based biophysical threshold thinking (maximum sustainable environmental impact per unit area).

While conceptualising the carrying capacity is in itself a challenge, measuring the amount of pressure that the Earth can sustain is an even more difficult undertaking because of the various uncertainties, ambiguities and subjectivities surrounding this issue (Hoekstra and Wiedmann, 2014). In presenting their approach to quantifying and measuring planetary boundaries, Rockström et al. (2009) employ a concept akin to carrying capacity, that of planetary boundaries. These boundaries "define the safe operating space for humanity with respect to the Earth system and are associated with the planet's biophysical subsystems and processes" (Rockström et al., 2009). Faced with vast knowledge gaps and quantification challenges, the attempt to define the exact planetary boundaries for various Earth-system processes is plagued by a high degree of uncertainty (Rockström et al., 2009).

\subsection{Implementing carrying capacity at farm level}

In the case of agriculture, the exceeding of the carrying capacity limit is becoming particularly evident and is a cause for concern (Rees and Wackernagel, 2013) - a fact that highlights the crucial importance of bearing in mind this issue when assessing environmental sustainability at farm level. The challenge when developing farm environmental performance indicators is therefore how to relate carrying- 
capacity considerations originating at planet (i.e. macro-) level and, more specifically, the associated absolute global biophysical thresholds, with the farm (i.e. micro-) level.

Basically, we can distinguish two levels at which the carrying-capacity constraint applies for ensuring sustainable development: that of the global ecosystem (planet Earth), and that of the local ecosystem underpinning the farm area (sub-ecosystem of the global ecosystem) (Lowe and Evans, 1995). The local ecosystem has a more or less narrowly defined local dimension. Depending on the environmentalissue/impact category considered, this ranges from a very local to a more regional level, and can also encompass a homogeneous ecosystem area inside a region or country (cf. also the issue of local carrying-capacity entitlement in the Discussion section). Both local and global carrying capacities are intrinsic characteristics of the ecosphere's closed system, and limiting factors for the economic activity in the technosphere (Wackernagel and Rees, 1997).

Complying with the carrying capacity constraints at both global and local ecosystem level is a prerequisite for achieving a sustainable state with no possibilities for compensation or substitution available between these two levels. Based on this distinction, and as proposed by Jan et al. (2012), we differentiate between the local and global environmental performance of a farm. Farm local and global environmental performances measure the extent to which a farm complies, respectively, with the local and global carrying-capacity constraints. The local environmental performance of a farm also possesses a regional character. The link with the regional scale occurs when the local carrying-capacity entitlement of the farm is quantified as explained in the discussion.

\section{Defining and measuring the global vs. local environmental performance of a farm}

Implementing global and local carrying-capacity constraints at farm level is the challenge posed by the development of farm environmental performance indicators. This section precisely defines and specifies the measures to be used when assessing the local and global dimension of a farm's environmental performance. As explained in Section 2.1, we propose the use of environmental performance indicators based on environmental variables that best represent the potential 
damage to the environment. The closer the environmental assessment is to the ultimate environmental impact, the more relatable the impact will be to environmental sustainability and carrying-capacity constraints. Despite this, unless the endpoint modelling is associated with a high level of certainty, the midpoint impact indicators will provide a more feasible solution, for the reasons already set out in Section 2.1.1.

\subsection{Local vs. global environmental performance of a farm}

At local ecosystem level, the use of an indicator termed "local environmental performance" and defined as the local environmental impact generation per unit of (local) farm area enables us to assess the intensity of the farm's environmental impact generation on its local ecosystem, and thus - when this is compared to the carrying capacity of the local ecosystem - its compliance with the said localecosystem carrying capacity. If the local environmental impact per unit area is greater than the carrying capacity of the local ecosystem, then the situation is unsustainable. While it is fairly easy to establish the link between carrying-capacity constraint and farm unit at local ecosystem level, this is not the case at global ecosystem level. Indeed, direct implementation of the global carrying-capacity constraint at farm level is a highly challenging if not impossible undertaking, requiring as it does an allocation of the planetary carrying capacity to each polluting unit (companies, households, etc.) of planet Earth. Such an allocation could not be implemented on an exclusively scientific basis, but would also need to bear in mind the preferences of society and interspatial equity, a fact which highlights the extreme complexity of such an allocation. Using a farm environmental intensity indicator (defined as the inverse of eco-efficiency) over the entire production chain up to the farm gate in order to measure global environmental performance enables us to tackle this problem and to indirectly link global-ecosystem carrying capacity with the farm unit. In point of fact, even if a low environmental intensity level does not guarantee that the absolute carrying-capacity thresholds at global ecosystem level will not be exceeded, a relative comparison among farms of the value of this indicator allows us to measure the relative contribution of each farm and its production chain to the reduction of environmental impact generation at global ecosystem level, and thus its contribution to compliance with carrying capacity at this level.

Whether a local or global carrying-capacity constraint, or indeed both types of constraint, apply for a given environmental issue depends on the scale (local or global) of environmental relevance of the impacts associated with the issue, i.e. the 
(local or global) level at which the environmental impacts ultimately affect carrying capacity. For some environmental issues, both local and global carrying-capacity constraints may be of relevance, while for others only one or the other may apply, as will be shown below.

The global/local farm environmental performance distinction proposed here on the basis of our theoretical considerations has already been suggested in the literature; in fact, various authors point out that environmental problems of a local and global nature must be considered separately with different indicator types when assessing a farm's environmental performance (Haas et al., 2000; van der Werf and Petit, 2002; de Boer, 2003; Halberg et al., 2005a; Payraudeau and van der Werf, 2005; Blonk et al., 2010; Jan et al., 2012).

Halberg et al. (2005a) make a substantial contribution in this respect, proposing the use of area-based indicators for environmental issues with a local dimension, and product-based indicators for those of a global nature. They also recommend that only those environmental impacts occurring at local farm level be included in the areabased indicator of local environmental performance. The product-based indicator of global environmental performance should for its part encompass the environmental impacts generated both at farm level and in the upstream stages of farm-input production, i.e. over the entire production chain up to the farm gate.

\subsection{Global environmental performance}

As mentioned previously, a farm's global environmental performance is measured by means of an indicator of environmental intensity over the entire production chain up to the farm gate. As Formula 1 below shows, environmental intensity is thus defined as the overall level of environmental impact generated throughout the entire production chain up to the farm gate per (bio-)physical unit of output produced by the farm.

\section{Formula 1}

Global environmental performance $=\frac{E I_{\text {glob }}}{\text { farm physical output }}$ $E I_{\text {glob }}$ : global environmental impact 
It is important to emphasise here that, for the reasons exposed in Section 3.1, it is necessary to use a biophysical output variable related to the basic functions of agriculture from a biophysical environmental perspective to avoid any biases induced by the use of monetary variables. A farm is conceptualized here as a biophysical transformation process of natural resources into biophysical outputs. Basically, three major categories of biophysical outputs or functions fulfilled by a farm can be distinguished: (i) food and feed production, (ii) biomass production, and (iii) maintenance of an open/cultivated landscape or any other environmental amenity. This latter function concerns only areas (such as mountain regions) where the natural conditions are particularly unfavourable for the production of agricultural commodities, and where society - for mainly social and environmental reasons - has an interest in maintaining an open cultivated landscape. An overview of possible biophysical output variables that can be used for different basic agricultural functions is provided in Table 1.

Table 1: Possible biophysical output variables for different basic agricultural functions.

\begin{tabular}{|c|c|c|c|}
\hline $\begin{array}{c}\text { Primary } \\
\text { Agricultural } \\
\text { Function }\end{array}$ & $\begin{array}{c}\text { Food \& Feed } \\
\text { Production }\end{array}$ & Biomass Production & $\begin{array}{c}\text { Maintenance of an } \\
\text { Open/Cultivated } \\
\text { Landscape }^{3}\end{array}$ \\
\hline $\begin{array}{l}\text { Biophysical } \\
\text { output } \\
\text { variable }\end{array}$ & $\begin{array}{l}\text { Product-based FU: } \\
\text { - Mass or volume FU, } \\
\text { such as kg or litre of a } \\
\text { particular agricultural } \\
\text { output } \\
\text { Nutrition-based FU: } \\
\text { For food: } \\
\text { - Digestible energy } \\
\text { content in MJ or } \\
\text { kilocalories } \\
\text { - Protein content } \\
\text { - Nutrient-score FUs } \\
\text { For feed : }\end{array}$ & $\begin{array}{l}\text { Product-based FU: } \\
\text { - Mass or volume of } \\
\text { biomass } \\
\text { Energy-based FU: } \\
\text { - Caloric output in } \\
\text { MJ } \\
\text { Transport function- } \\
\text { based FU: } \\
\text { - Kilometres or miles } \\
\text { of distance travelled } \\
\text { with biomass- } \\
\text { produced fuel }\end{array}$ & $\begin{array}{l}\text { Area-based FU: } \\
\text { - Hectares of } \\
\text { landscape under } \\
\text { cultivation }\end{array}$ \\
\hline
\end{tabular}
${ }^{3}$ Both on- and off-farm landscape maintenance must be taken into account in order to ensure
spatial system boundary consistency (for further details, see Section 2.3.2). 


\begin{tabular}{|l|l|l|l|}
\hline & - Digestible & \\
energy/protein output & & \\
available to the & & \\
animal species & & \\
consuming the feed & & \\
\hline
\end{tabular}

The majority of farms typically produce several outputs associated with one or more primary functions of agriculture. This raises the question of how best to deal with these multiple heterogeneous outputs. If the outputs produced contribute to the same single function, then a common biophysical unit (e.g. digestible energy output in the case of the food provision function) may be found to aggregate the different outputs. If no common unit can be found, then the entire range of outputs should be addressed, either by allocating the environmental impacts to each output/function, thereby switching to an environmental-intensity calculation at product/function level (instead of at whole-farm level), or by using an approach such as data envelopment analysis (see Coelli et al., 2005), which allows for an objective aggregation of these multiple outputs expressed in different units.

As is obvious from the definition of farm global environmental performance, we take a production-chain - more specifically, a cradle-to-farm-gate - approach. We therefore take account not only of those environmental impacts generated on-farm, but also of those generated off-farm in the farm upstream stages, during the manufacture and transport of farm inputs. This ensures that no environmental impact goes unnoticed. The LCA method is therefore particularly well suited to assessing those environmental impacts considered in the global environmental performance indicator.

\subsection{Local environmental performance}

Local environmental performance focuses exclusively on the environmental impacts generated on-farm at local-ecosystem level (Halberg et al., 2005a). Here, the focus is on environmental impacts arising from emissions generated locally by the activities of the farm in question, and resulting in environmental impacts at the immediate local/regional ecosystem level (e.g. watershed) of the farm in question. Although other farms or polluters may also generate environmental impacts in the area of the farm investigated, they are not taken into account in the local environmental performance of the farm itself. Moreover, although emissions generated elsewhere in 
the farm's supply chain are not to be taken into account when determining the farm's local environmental performance, they could be used for separate assessment of the local environmental performance of other actors in the chain. Indeed, any farm purchasing inputs (e.g. mineral fertilisers or feed) off- farm, or moving part of its livestock to another background farm, is contributing to the creation of local environmental impacts elsewhere in the production chain. To give an example, if a farm uses commercial mineral fertilisers, the environmental impacts associated with the production and transport of this input should not be included in the farm's local environmental performance assessment, because the emissions from the production of the fertilizer are generated elsewhere than on the farm itself; however, the local environmental impacts arising from the emissions associated with the farm-level application of the fertilizer must be taken into account when evaluating the farm's local environmental performance. Ideally, it would be possible to estimate the local environmental performance in all links of the chain, from cradle to farm gate. Such an assessment, however, would pose quite a challenge, and would very likely fail owing to (i) its complexity, especially in terms of defining system boundaries and quantifying environmental impacts that are local and those that are not, (ii) the heterogeneous nature of the activities in the upstream stages of farm production, and (iii) the associated limited data available for such a quantification.

The local carrying-capacity constraint can be understood as the maximum environmental impact per unit of farmland area that the local ecosystem is capable of sustaining. Local environmental performance is measured by means of an areabased indicator quantifying the level of environmental impacts generated by the farm at local (i.e. farm) level per unit of local farm area, as shown in Formula 2:

\section{Formula 2}

Local environmental performance $=\frac{E I_{\text {loc }}}{\text { farmland area }}$ $E I_{l o c}$ : local environmental impact

Environmental impact per hectare of area should be less than the carrying capacity of the local ecosystem. For the reasons outlined in Sections 4.1 and 4.6, determining the local carrying capacity is not a precondition for implementing the local environmental performance indicator proposed by us. 


\subsection{Environmental issues to be considered at global vs. local level}

Generally speaking, environmental issues constituting global-level concerns are those connected with the depletion of the Earth's non-renewable resources as well as emissions that spread from farms to the global ecosystem, causing global-scale problems once a certain global threshold for environmental-impact generation has been exceeded (e.g. fossil energy use and greenhouse-gas emissions) (Haas et al., 2000; van der Werf and Petit, 2002; Halberg et al., 2005a; Payraudeau and van der Werf, 2005). In our framework, the following issues will therefore be considered exclusively at global level: non-renewable-energy use, global-warming potential, ozone depletion, abiotic resource depletion (e.g. mined resources such as phosphorus or potassium), and land use (land competition). The environmental issues to be borne in mind when quantifying local environmental performance are those for which farm environmental impacts exert an impact chiefly on the local ecosystem scale, namely eutrophication, acidification, terrestrial and aquatic ecotoxicity, human toxicity, photo-oxidant formation, biodiversity, water use, and soil quality. For these issues, minimising local environmental-impact generation per unit of farm area is key for ensuring a sustainable state.

In the globalised economy of the $21^{\text {st }}$ century, however, international trade may ultimately cause the globalisation of environmental issues that were originally chiefly of local relevance (Bare, 2014). Furthermore, through the complex interconnectedness of natural processes, what were originally local environmental issues can spread far and wide, thereby also putting pressure on the global carrying capacity of the planet. Acidification and eutrophication phenomena, for example, primarily influence the environment close to the source of nutrient emission, but may also affect the environment at several hundred kilometres' distance (Payraudeau and van der Werf, 2005). To ensure the taking into account of (i) any issues that might be important at both local and global ecosystem level as well as (ii) off-farm impacts created by environmental issues of a primarily local nature, the latter types of environmental issues should also be considered from a global perspective. This will prevent the potential shifting of environmental impacts from the farm stage to the offfarm upstream stages of the life cycle, allowing us to form a complete picture of farm environmental performance. Global consideration of the environmental issues that are primarily of local relevance would not be necessary if we also measured local environmental performance in each upstream link of the production chain. As already 
mentioned in Section 4.3, however, such an assessment would be very challenging, as well as highly unlikely to succeed.

\subsection{Practical implementation}

The actual implementation of our framework for measuring farm environmental performance involves several steps. In the first step, a classic cradle-to-farm-gate LCA is conducted. As an environmental impact assessment method that can be used to comprehensively determine impacts across the entire cradle-to-farm-gate link of the food chain, LCA is the most appropriate method for measuring farm global environmental performance, given that it holistically quantifies the generation of overall environmental impacts associated with farm activity. Since the local environmental impacts can be derived from the global ones by their on-farm and offfarm breakdown, LCA results can also be used for the assessment of local environmental performance. Before conducting the LCA, the environmental issues to be considered should be selected. In order to provide a complete environmental performance profile, all relevant environmental issues at global as well as local scale must be taken into account. We are, however, aware that in most empirical applications of our framework, the choice of environmental issues will depend on data availability or data-collection feasibility. Nevertheless, because of potential trade-offs between environmental issues, the assessment should be as complete as possible. In the second step, once the cradle-to-farm-gate impacts have been assessed, they are decomposed to their on- and off-farm parts. Next, farm global environmental performance is quantified by dividing the cradle-to-farm-gate environmental impacts by the farm's biophysical output(s). In step four, the farm's local environmental performance is estimated by dividing on-farm environmental impact generation by the farm's area. Finally, global and local environmental performance indicators are compared among the farms studied, with the goal of learning from the best performers.

\subsection{A benchmarking, and, hence relative, approach}

The concept of an ecosystem carrying-capacity constraint is associated with the physical threshold thinking. The problem posed by the impossibility of defining a physical threshold (carrying capacity) for the global ecosystem that would apply at farm level (for further thoughts on this subject, cf. also Section 4.1) can be circumvented by using an environmental intensity indicator over the entire production 
chain up to the farm gate, combined with a benchmarking approach. Proceeding in this manner means adopting a relative approach for the assessment of global environmental performance. The said approach consists in benchmarking farms against one another in terms of their environmental intensity over the entire production chain up to the farm gate, and explaining why some farms perform better than others.

Even if it were possible to define physical thresholds for the carrying capacity of the local ecosystem that should not be exceeded, due to the uncertainties and difficulties associated with determining such thresholds (e.g. Steffen et al., 2015), here, too, we prefer to adopt a relative approach consisting in a comparison of the farms in terms of environmental-impact generation at local farm level per unit of area, and an analysis of the causes of the observed heterogeneity. Our choice of a relative approach for measuring global and local environmental performance does not call into question the appropriateness and usefulness of the carrying-capacity concept for the definition and measurement of environmental performance. In this paper, however, the carrying-capacity concept represents just the starting point of our theoretical considerations regarding the development of a framework for measuring farm environmental performance, especially for the local/global distinction we propose. The indicators developed do not directly incorporate the carrying capacities, however.

Through the use of a benchmarking-based, and hence relative, approach for assessing farm environmental performance, sustainability comes to be viewed "as a dynamic process in which the targets have to be continuously checked and improved, or as a philosophy that permanently tends towards improvement' (Callens and Tyteca, 1999).

\section{Discussion}

The framework that we propose for defining and measuring farm environmental performance is based on the environmental sustainability concept, approached from an ecological perspective. More precisely, it builds on the intrinsically related concept of ecosystem carrying capacity, thereby making a substantial contribution to the assessment of farm environmental sustainability. The framework outlines and specifies the appropriate indicators for assessing the environmental performance of a farm. By distinguishing between the carrying capacity of the local vs. global ecosystem and proposing relevant environmental performance indicators measuring the relative compliance of a farm with these two carrying-capacity constraints, it avoids the short- 
sighted focusing of attention on just one ecosystem level at the expense of the other. In addition, the framework identifies environmental issues that should be considered at a global and/or local level, and contributes to the discussion of FUs from an LCA perspective. Last but not least, the framework is universally implementable, regardless of farm type/activities or location. Despite the strengths of this framework, several limitations can be identified with respect to its implementation.

The first major limitation of our framework is the relative nature of the approach used to assess the global and local environmental performance of the farm. By relying on environmental intensity - the inverse of eco-efficiency - for the measurement of global environmental performance, we assess relative rather than absolute environmental sustainability (Bjørn and Hauschild, 2013). This implies that there is no guarantee of reaching an absolute sustainable state, for the following reasons: Firstly, scientific evidence shows that the anthropogenic perturbation levels for a number of environmental issues are higher than the carrying capacity of planet Earth, thus implying that an unsustainable state of the environment has already been reached (Steffen et al., 2015). According to Bjørn and Hauschild (2013), eco-efficiency improvement factors ranging from 4 to as high as 50 have been proposed in the literature in order to keep the environmental impacts generated globally by human activity within the carrying capacity. The scale of these eco-efficiency improvement factors shows how unlikely they are to be achieved. Secondly, growth in population and per capita material affluence lead to a rise in global environmental impacts (Bjørn and Hauschild, 2013; Bjørn and Hauschild, 2015), which wipes out the positive effects of eco-efficiency improvements in terms of a reduction in environmental impacts. Last but not least, eco-efficiency improvements have also been shown to lead to direct and indirect rebound effects which offset the reduction in environmental impacts resulting from the higher degree of eco-efficiency (Hueseman and Hueseman, 2007). For these reasons, the eco-efficiency approach cannot be considered a panacea for reducing environmental impacts below the carrying capacity.

Although the local environmental performance indicator - defined as the local environmental impact generation per hectare of area - does not rely on eco-efficiency, like eco-efficiency it still belongs to the group of indicators termed "relative environmental sustainability indicators (RESI)" by Bjørn et al. (2016), and that do not enable to draw conclusions in terms of sustainability on an absolute scale. Furthermore, our local environmental performance indicator has another limitation, in that it fails to take account of the differences in vulnerability between different local ecosystems, ignoring the fact that carrying capacity may vary substantially from one 
local ecosystem to another. This issue should be borne in mind when comparing the local environmental performance of different farms.

Recently, LCA-based works were conducted with the aim of incorporating carrying capacities in environmental performance indicators, and thus of switching from relative to absolute environmental sustainability indicators (cf. e.g. Bjørn and Hauschild, 2015; Bjørn et al., 2015a; 2016). Bjørn and Hauschild (2015) developed carrying-capacitybased normalisation references that can be used in LCAs to aggregate environmental impact scores across impact categories. The said normalisation references (NRs) are defined as the carrying capacity per year for a given impact category in a given region, divided by the population of this region (e.g. $\mathrm{kg} \mathrm{CO}_{2}$-eq per person and year; Bjørn and Hauschild, 2015). They allow us to convert the LCA midpoint indicator scores for each impact category into person equivalents. One "person equivalent" can be interpreted as "an environmental impact generation equivalent to the annual personal share of the carrying capacity for impact category i" (adapted from Bjørn and Hauschild, 2015). These person equivalents can then be aggregated across all impact categories (Bjørn and Hauschild, 2015). Bjørn et al. (2016) included carrying capacity as a sustainable reference value in spatially resolved characterisation factors used for environmental impacts assessment. The indicator derived by multiplying the characterisation factor by emission or resource use then expresses "the area equivalent of fully occupied capacity" (Bjørn et al., 2016). This area can be compared to "the actual area of the ecosystem affected" (Bjørn et al., 2016).

From a purely conceptual perspective, carrying capacities could easily be integrated in the farm environmental performance indicators of our framework, albeit in a different manner from that proposed in Bjørn and Hauschild (2015) or Bjørn et al. (2016). Global carrying capacities specific to each impact category would first need to be allocated to various human needs (e.g. food, housing, clothing, mobility). This entitlement would imply valuation that is normative in nature, given that "it inherently involves value judgement of anthropogenic systems that are competing for the occupation of the same finite carrying capacity" (Bjorn et al., 2015b). Based on the carrying capacity entitlement for each need, as well as on the global biophysical output (e.g. MJ digestible energy) that must be produced in order to satisfy global human needs, it would be possible to estimate for each need a maximum global environmental intensity (termed a "global environmental intensity entitlement") that, in order to comply with the global ecosystem's carrying capacity, must not be exceeded. The global environmental intensity of a farm in the cradle-to-farm-gate link of the food chain could then be divided by the global environmental intensity entitlement for food production in this link. This would result in a performance variable indicating whether or not the maximum 
permissible global environmental intensity has been exceeded, and if so, by how much the farm's global environmental intensity should be reduced in order to comply with the carrying-capacity entitlement. The approach to integrating carrying capacity in the local performance indicator would be similar. The local carrying-capacity entitlement would be estimated by allocating the carrying capacity of the local/regional ecosystem to the different anthropogenic systems competing for this carrying capacity. This allocation would be based on the relative perceived value of each competing system (Bjorn et al., 2015b). The farm's local environmental impact generation per hectare would be divided by the local carrying-capacity entitlement (defined as the maximum permissible environmental impact generation per hectare). The indicator thus derived would measure the degree to which a farm complies with its local carrying-capacity entitlement.

As is obvious from these initial considerations, it is conceptually possible to incorporate carrying capacities in the performance indicators proposed by us. Quantifying the carrying-capacity entitlement for the different impact categories and on the two different scales (global vs. local) considered is expected to be a highly challenging process that is fraught with uncertainties, especially given the dynamic nature of carrying capacities (Bjørn and Hauschild, 2015). The practical implementation of these conceptual considerations should be the subject of future research.

The second restriction of our framework is its reliance on the LCA approach, which suffers from some limitations. For one thing, assessments for some categories of impact are still in the research and development phase (Pashaei Kamali et al., 2014; Bare, 2014). Moreover, LCAs can suffer from high levels of uncertainty owing to the simplified modelling of complex cause-effect chains and the large quantities of measured and simulated data involved (Hellweg and i Canals, 2014). Furthermore, since LCA is developed as a global-impact assessment tool, its use at local-impact level poses a challenge, due primarily to the absence of spatial differentiation in characterisation modelling in commonly used LCIA approaches (Potting and Hauschild, 2006; Blonk et al., 2010). Spatial differentiation would be especially useful for environmental issues of local relevance, since it would increase the accuracy and discriminating power of LCIA by introducing a site-dependent or site-specific impact assessment (Potting and Hauschild, 2006).

The third limitation of our framework concerns the challenges associated with the practical implementation of the measurement of local environmental performance. The on- and off-farm breakdown is not available as such, and must be performed in 
great detail at the process level, which takes time and requires a very good understanding of the processes involved. Moreover, because this type of consideration of local environmental performance is new, there is no possibility to compare it with values found in the literature.

The final limitation of the framework is that the proposed farm environmental performance assessment focuses exclusively on the cradle-to-farm-gate link, without extending the scope of the environmental assessment beyond the farm gate. It therefore provides no insights into the impacts resulting from the processing, distribution, consumption, and waste phases of the food life cycle. We excluded the farm-gate-to-grave link of the food chain because the farmer has very little (if any) influence on what happens in the downstream stages (processing, retail, and consumption) of the food chain. Although a majority of the food chain's environmental impact creation occurs at farm level, we should be aware that in the globalised world, food is produced, traded, consumed, and disposed of at different localities that may be geographically very distant from one other. In order to gain a comprehensive picture of the environmental impact of the entire food chain, the cradle-to-farm-gate assessment should be supplemented by a detailed quantification of the impacts occuring in the post-farm life-cycle stages.

\section{Conclusions}

Environmental sustainability is an ecological concept closely connected with the ecosystem carrying capacity (constraint), which is a biophysical concept relating to the maximum damage that an ecosystem can sustain. Indicators used to assess farm environmental performance must therefore (i) be biophysical in nature and (ii) best represent the damage to the environment. The carrying-capacity constraint applies at two levels: that of the global ecosystem, and that of the local ecosystem (sub-ecosystem of the global ecosystem). Compliance with the carrying-capacity constraints at both levels is a prerequisite for sustainable development, with no possibility of compensation or substitution between these two levels. Implementation of the global and local carrying-capacity constraints at farm level results in the differentiation between two different types of farm environmental performance (global vs. local) and related indicators. These two indicator types directly or indirectly measure the relative extent to which a farm complies with the carrying-capacity constraints of the global vs. local ecosystem, and differ from one another not only in 
terms of their definition, but also with respect to the spatial system boundaries of the underlying environmental assessment and the environmental issues considered.

Whereas farm global environmental performance is measured by the environmental intensity of the farm across the entire production chain up to the farm gate, farm local environmental performance is defined as the environmental impact generated at local (i.e. farm) level per unit of (local) farm area.

The implementation of separate local and global environmental performance indicators should above all prevent the shifting of environmental problems from the local to the global scale and vice versa. Last but not least, this framework allows us to analyse potential synergies and trade-offs between the various dimensions of the environmental performance of a farm, and in this sense highlights the complexity of the environmental sustainability concept, which cannot be reduced to a single "one size fits all" indicator.

\section{Acknowledgements}

The order in which the authors are listed follows the "sequence determines credit" approach (Tscharntke et al., 2007), rather than the "first-last-author emphasis" norm.

The research presented in this paper was conducted as part of the ECON'ENTAL project of the Swiss National Science Foundation (SNSF) National Research Programme 69. Financial support from the Swiss National Science Foundation (Grant Number 406940_145173; Applicant: Pierrick Jan) is gratefully acknowledged.

\section{References}

BARE, J. C., 2014. Development of impact assessment methodologies for environmental sustainability. Clean Technologies and Environmental Policy, $16,681-690$.

BARE, J. C., HOFSteTteR, P., PENNINGTON, D. W. \& DE HAES, H. A. U., 2000. Midpoints versus endpoints: the sacrifices and benefits. The International Journal of Life Cycle Assessment, 5, 319-326.

BASSET-MENS, C. \& VAN DER WERF, H. M., 2005. Scenario-based environmental assessment of farming systems: the case of pig production in France. Agriculture, Ecosystems \& Environment, 105, 127-144.

BEUKES, P., SCARSBROOK, M., GREGORINI, P., ROMERA, A., CLARK, D. \& CATTO, W., 2012. The relationship between milk production and farm-gate nitrogen surplus for the Waikato region, New Zealand. Journal of environmental management, 93, 44-51.

BJØRN, A. \& HAUSCHILD, M.Z., 2013. Absolute versus relative environmental sustainability. Journal of Industrial Ecology, 17, 321-332. 
BJØRN, A. \& HAUSCHILD, M.Z., 2015. Introducing carrying capacity-based normalisation in LCA: framework and development of references at midpoint level. International Journal of Life Cycle Assessment, 20, 1005-1018.

BJØRN, A., DIAMOND, M., OWSIANIAK, M., VERZAT, B. \& HAUSCHILD, M.Z., 2015a. Strengthening the link between Life Cycle Assessment and indicators for absolute Sustainability to support development within planetary doundaries. Environmental Science and Technology, 49, 6370-6371.

BJØRN, A., HAUSCHILD, M. Z., RØPKE, I. \& RICHARDSON, K., 2015b. Better, but good enough? Indicators for absolute environmental sustainability in a life cycle perspective. Lyngby: DTU Management Engineering. (DTU Management Engineering. PhD thesis; No. 8.2015).

BJøRN, A., MARGNI, M., ROY, P.O., BULLE, C. \& HAUSCHILD, M.Z., 2016. A proposal to measure absolute environmental sustainability in life cycle assessment. Ecological Indicators, 63, 1-13.

BLONK, H., SCHOLTEN, J. \& BROEKEMA, R., 2010. Measuring the Sustainability Performance of Agro-Food Chain Initiatives: A Method for Estimating the Potential Sustainability Performance of Initiatives in which TransForum Participated. Gouda: Blonk Milieu Advies BV.

BOCKSTALLER, C. \& GIRARDIN, P., 2003. How to validate environmental indicators. Agricultural Systems, 76, 639-653.

BROMLEY, D. W., 1989. Entitlements, missing markets, and environmental uncertainty. Journal of Environmental Economics and Management, 17, 181194.

BROWNE, S., 2012. Industrial Solutions for a Sustainable Future. United Nations Industrial Development Organization. Oxon: Routledge.

BYSTRICKY, M., ALIG, M., NEMECEK, T. \& GAILLARD, G., 2014. Ökobilanz ausgewählter Schweizer Landwirtschaftsprodukte im Vergleich zum Import. Zurich: Agroscope, Institut für Nachhaltigkeitswissenschaften INH.

CABEZA GUTÉS, M., 1996. The concept of weak sustainability. Ecological Economics, 17, 147-156.

CALLENS, I. \& TYTECA, D., 1999. Towards indicators of sustainable development for firms: a productive efficiency perspective. Ecological Economics, 28, 4153.

CASEY, J. \& HOLDEN, N., 2005. Analysis of greenhouse gas emissions from the average Irish milk production system. Agricultural systems, 86, 97-114.

CASEY, J. \& HOLDEN, N., 2006. Quantification of GHG emissions from sucker-beef production in Ireland. Agricultural Systems, 90, 79-98.

CEDERBERG, C. \& MATTSSON, B., 2000. Life cycle assessment of milk production-a comparison of conventional and organic farming. Journal of Cleaner production, 8, 49-60.

COELLI, T., LAUWERS, L. \& VAN HUYLENBROECK, G., 2007. Environmental efficiency measurement and the materials balance condition. Journal of Productivity Analysis, 28, 3-12.

COELLI, T. J., RAO, D. S. P., O'DONNELL, C. J. \& BATTESE, G. E., 2005. An Introduction to Efficiency and Productivity Analysis. New York: Springer Science \& Business Media.

DALE, V. H. \& POLASKY, S., 2007. Measures of the effects of agricultural practices on ecosystem services. Ecological Economics, 64, 286-296.

DE BOER, I. J. M., 2003. Environmental impact assessment of conventional and organic milk production. Livestock Production Science, 80, 69-77.

EIDE, M. H., 2002. Life cycle assessment (LCA) of industrial milk production. The International Journal of Life Cycle Assessment, 7, 115-126.

FARLEY, J., 2008. The role of prices in conserving critical natural capital. Conservation Biology, 22, 1399-1408. 
FOLEY, J. A., DEFRIES, R., ASNER, G. P., BARFORD, C., BONAN, G., CARPENTER, S. R., CHAPIN, F. S., COE, M. T., DAILY, G. C. \& GIBBS, H. K., 2005. Global consequences of land use. Science, 309, 570-574.

GERBENS-LEENES, P., NONHEBEL, S. \& KROL, M., 2010. Food consumption patterns and economic growth. Increasing affluence and the use of natural resources. Appetite, 55, 597-608.

GERBER, P., VELLINGA, T., OPIO, C., HENDERSON, B. \& STEINFELD, H., 2010. Greenhouse Gas Emissions from the Dairy Sector. A Life Cycle Assessment. Rome: Food and Agriculture Organization of the United Nations.

GODFRAY, H. C. J., BEDDINGTON, J. R., CRUTE, I. R., HADDAD, L., LAWRENCE, D., MUIR, J. F., PRETTY, J., ROBINSON, S., THOMAS, S. M. \& TOULMIN, C., 2010. Food security: the challenge of feeding 9 billion people. Science, $327,812-818$.

GOODLAND, R., 1995. The concept of environmental sustainability. Annual Review of Ecology and Systematics, 26, 1-24.

GOODLAND, R. \& DALY, H., 1996. Environmental sustainability: universal and nonnegotiable. Ecological Applications, 6, 1002-1017.

GROOT, J. C., ROSSING, W. A. \& LANTINGA, E. A., 2006. Evolution of farm management, nitrogen efficiency and economic performance on Dutch dairy farms reducing external inputs. Livestock Science, 100, 99-110.

HAAS, G., WETTERICH, F. \& GEIER, U., 2000. Life cycle assessment framework in agriculture on the farm level. The International Journal of Life Cycle Assessment, 5, 345 - 348.

HALBERG, N., VAN DER WERF, H. M., BASSET-MENS, C., DALGAARD, R. \& DE BOER, I. J., 2005a. Environmental assessment tools for the evaluation and improvement of European livestock production systems. Livestock Production Science, 96, 33-50.

HALBERG, N., VERSCHUUR, G. \& GOODLASS, G., 2005b. Farm level environmental indicators; Are they useful?: An overview of green accounting systems for European farms. Agriculture, Ecosystems \& Environment, 105, 195-212.

HELLWEG, S. \& I CANALS, L. M., 2014. Emerging approaches, challenges and opportunities in life cycle assessment. Science, 344, 1109-1113.

HOANG, V.-N. \& ALAUDDIN, M., 2012. Input-orientated data envelopment analysis framework for measuring and decomposing economic, environmental and ecological efficiency: an application to OECD agriculture. Environmental and Resource Economics, 51, 431-452.

HOANG, V.-N. \& COELLI, T., 2011. Measurement of agricultural total factor productivity growth incorporating environmental factors: a nutrients balance approach. Journal of Environmental Economics and Management, 62, 462474.

HOANG, V.-N. \& RAO, D. P., 2010. Measuring and decomposing sustainable efficiency in agricultural production: a cumulative exergy balance approach. Ecological Economics, 69, 1765-1776.

HOEKSTRA, A. Y. \& WIEDMANN, T. O., 2014. Humanity's unsustainable environmental footprint. Science, 344, 1114-1117.

HOKAZONO, S. \& HAYASHI, K., 2015. Life cycle assessment of organic paddy rotation systems using land- and product-based indicators: a case study in Japan. The International Journal of Life Cycle Assessment, 20, 1061-1075.

HOSPIDO, A., MOREIRA, M. \& FEIJOO, G., 2003. Simplified life cycle assessment of Galician milk production. International Dairy Journal, 13, 783-796.

HUESEMAN, M.H. \& HUESEMAN, J.A., 2007. Will progress in science and technology avert or accelerate global collapse? A critical analysis and policy recommendations. Environment, Development and Sustainability, 10, 787825. 
ISO, 2006. The New International Standards for Life Cycle Assessment: ISO 14040 and ISO 14044. Geneva: ISO.

JAN, P., DUX, D., LIPS, M., ALIG, M. \& DUMONDEL, M., 2012. On the link between economic and environmental performance of Swiss dairy farms of the alpine area. The International Journal of Life Cycle Assessment, 17, 706-719.

JAN, P., CALABRESE, C. \& LIPS, M., 2015. Determinants of Nitrogen Surplus at Farm Level in Swiss Agriculture. Contributed Paper prepared for presentation at the 29th International Conference of Agricultural Economists, Università Degli Studi di Milano, Milano, 8 - 14 August 2015.

JOLLIET, O., MÜLLER-WENK, R., BARE, J., BRENT, A., GOEDKOOP, M., HEIJUNGS, R., ITSUBO, N., PEÑA, C., PENNINGTON, D. \& POTTING, J., 2004. The LCIA midpoint-damage framework of the UNEP/SETAC life cycle initiative. The International Journal of Life Cycle Assessment, 9, 394-404.

KÁROLY, K., 2011. Rise and fall of the concept sustainability. Journal of Environmental Sustainability, 1, 1.

KIRCHLER, E., FISCHER F. AND HÖLZL, E., 2010. Price and its relation to objective and subjective product quality: evidence from the Austrian market. Journal of Consumer Policy, 33, 275-286.

KORSAETH, A., JACOBSEN, A., ROER, A.-G., HENRIKSEN, T., SONESSON, U., BONESMO, H., SKJELVÅG, A. \& STRØMMAN, A. H., 2012. Environmental life cycle assessment of cereal and bread production in Norway. Acta Agriculturae Scandinavica, Section A - Animal Science, 62, 242-253.

KRISTENSEN, E. S. \& HALBERG, N., 1997. A systems approach for assessing sustainability in livestock farms. Livestock farming systems. More than food production.

KULAK, M., NEMECEK, T., FROSSARD, E., CHABLE, V. \& GAILLARD, G., 2014. Life cycle assessment of bread from several alternative food networks in Europe. Journal of Cleaner Production, 90, 104-113.

KUOSMANEN, T. \& KORTELAINEN, M., 2005. Measuring eco-efficiency of production with data envelopment analysis. Journal of Industrial Ecology, 9, 59-72.

LAUWERS, L., 2009. Justifying the incorporation of the materials balance principle into frontier-based eco-efficiency models. Ecological Economics, 68, 16051614.

LOWE, E. A. \& EVANS, L. K., 1995. Industrial ecology and industrial ecosystems. Journal of Cleaner Production, 3, 47-53.

MATSON, P. A., PARTON, W. J., POWER, A. \& SWIFT, M., 1997. Agricultural intensification and ecosystem properties. Science, 277, 504-509.

MICHA, E. \& HEANUE, K., 2015. Profiling farm systems according to their sustainable performance: the Irish livestock sector. Contributed Paper prepared for presentation at the 89th Annual Conference of the Agricultural Economics Society, University of Warwick, England, 13 - 15 April 2015.

MORELLI, J., 2011. Environmental sustainability: a definition for environmental professionals. Journal of Environmental Sustainability, 1, 2.

MU, W., VAN MIDDELAAR, C. E., BLOEMHOF, J. M. \& DE BOER, I. J., 2014. Benchmarking the environmental performance of specialized dairy production systems: selection of a set of indicators. In: SCHENCK, R., HUIZENGA, D. (Eds.), Proceedings of the 9th International Conference on Life Cycle Assessment in the Agri-Food Sector (LCA Food 2014), 8-10 October 2014, San Francisco, USA, pp. 872-879.

NEMECEK, T., VON RICHTHOFEN, J.-S., DUBOIS, G., CASTA, P., CHARLES, R. \& PAHL, H., 2008. Environmental impacts of introducing grain legumes into European crop rotations. European Journal of Agronomy, 28, 380-393. 
NEVENS, F., VERBRUGGEN, I., REHEUL, D. \& HOFMAN, G., 2006. Farm gate nitrogen surpluses and nitrogen use efficiency of specialized dairy farms in Flanders: Evolution and future goals. Agricultural Systems, 88, 142-155.

NIELSEN, A. H. \& KRISTENSEN, I. S., 2005. Nitrogen and phosphorus surpluses on Danish dairy and pig farms in relation to farm characteristics. Livestock Production Science, 96, 97-107.

OENEMA, O. \& PIETRZAK, S., 2002. Nutrient management in food production: achieving agronomic and environmental targets. AMBIO: A Journal of the Human Environment, 31, 159-168.

PASHAEI KAMALI, F., MEUWISSEN, M. P., DE BOER, I. J., STOLZ, H., JAHRL, I., GARIBAY, S. V., JACOBSEN, R., DRIESEN, T. \& LANSINK, A. G. O., 2014. Identifying sustainability issues for soymeal and beef production chains. Journal of Agricultural and Environmental Ethics, 27, 949-965.

PAYRAUDEAU, S. \& VAN DER WERF, H. M., 2005. Environmental impact assessment for a farming region: a review of methods. Agriculture, Ecosystems \& Environment, 107, 1-19.

PELLETIER, N. \& TYEDMERS, P., 2011. An ecological economic critique of the use of market information in life cycle assessment research. Journal of Industrial Ecology, 15, 342-354.

POTTING, J. \& HAUSCHILD, M., 2006. Spatial differentiation in life cycle impact assessment: a decade of method development to increase the environmental realism of LCIA. The International Journal of Life Cycle Assessment, 11, 1113.

POWER, A., 2010. Ecosystem services and agriculture: tradeoffs and synergies. Philosophical Transactions of the Royal Society B - Biological Sciences, 365, 2959-2971.

REBITZER, G., EKVALL, T., FRISCHKNECHT, R., HUNKELER, D., NORRIS, G., RYDBERG, T., SCHMIDT, W.-P., SUH, S., WEIDEMA, B. P. \& PENNINGTON, D., 2004. Life cycle assessment: part 1: framework, goal and scope definition, inventory analysis, and applications. Environment International, 30, 701-720.

REES, W. E., 1996. Revisiting carrying capacity: area-based indicators of sustainability. Population and Environment, 17, 195-215.

REES, W. E. \& WACKERNAGEL, M., 2013. The shoe fits, but the footprint is larger than Earth. PLoS Biology, 11, e1001701.

REINHARD, S., LOVELL, C. K. \& THIJSSEN, G., 1999. Econometric estimation of technical and environmental efficiency: an application to Dutch dairy farms. American Journal of Agricultural Economics, 81, 44-60.

ROBINSON, J., 2004. Squaring the circle? Some thoughts on the idea of sustainable development. Ecological Economics, 48, 369-384.

ROCKSTRÖM, J., STEFFEN, W., NOONE, K., PERSSON, Å., CHAPIN, F. S., LAMBIN, E. F., LENTON, T. M., SCHEFFER, M., FOLKE, C. \& SCHELLNHUBER, H. J., 2009. A safe operating space for humanity. Nature, $461,472-475$.

SCHAU, E. \& FET, A., 2008. LCA studies of food products as background for environmental product declarations. The International Journal of Life Cycle Assessment, 13, 255-264.

SCHRÖDER, J., AARTS, H., TEN BERGE, H., VAN KEULEN, H. \& NEETESON, J., 2003. An evaluation of whole-farm nitrogen balances and related indices for efficient nitrogen use. European Journal of Agronomy, 20, 33-44.

SCHULZE, H., SPILLER, A., BÖHM, J. AND DE WITTE, T., 2008. Is stinginess really $\mathrm{cool}$ ? Price-quality relations of brands and private labels in the food market. German Journal of Agricultural Economics, 57(6), 299-310.

STEFFEN, W., RICHARDSON, K., ROCKSTRÖM, J., CORNELL, S. E., FETZER, I., BENNETT, E. M., BIGGS, R., CARPENTER, S. R., DE VRIES, W., DE WIT, 
C. A., FOLKE, C., GERTEN, D., HEINKE, J.,MACE, G.M., PERSSON, L.M., RAMANATHAN, V., REYERS, B. \& SORLIN, S., 2015. Planetary boundaries: guiding human development on a changing planet. Science, 347, 736-746.

THOMA, G., POPP, J., NUTTER, D., SHONNARD, D., ULRICH, R., MATLOCK, M., KIM, D. S., NEIDERMAN, Z., KEMPER, N. \& EAST, C., 2013. Greenhouse gas emissions from milk production and consumption in the United States: a cradle-to-grave life cycle assessment circa 2008. International Dairy Journal, 31, S3-S14.

THOMASSEN, M., VAN CALKER, K., SMITS, M., IEPEMA, G. \& DE BOER, I., 2008. Life cycle assessment of conventional and organic milk production in the Netherlands. Agricultural systems, 96, 95-107.

THOMASSEN, M. A., DOLMAN, M. A., VAN CALKER, K. J. \& DE BOER, I. J. M., 2009. Relating life cycle assessment indicators to gross value added for Dutch dairy farms. Ecological Economics, 68, 2278-2284.

TSCHARNTKE, T., HOCHBERG, M. E., RAND, T. A., RESH, V. H. \& KRAUSS, J., 2007. Author sequence and credit for contributions in multiauthored publications. PLoS Biology, 5, e18.

TURNER, R. \& DAILY, G., 2008. The ecosystem services framework and natural capital conservation. Environmental and Resource Economics, 39, 25-35.

VAN DER WERF, H. M., GARNETT, T., CORSON, M. S., HAYASHI, K., HUISINGH, D. \& CEDERBERG, C., 2014. Towards eco-efficient agriculture and food systems: theory, praxis and future challenges. Journal of Cleaner Production, 73, 1-9.

VAN DER WERF, H. M., KANYARUSHOKI, C. \& CORSON, M. S., 2009. An operational method for the evaluation of resource use and environmental impacts of dairy farms by life cycle assessment. Journal of Environmental Management, 90, 3643-3652.

VAN DER WERF, H. M. \& PETIT, J., 2002. Evaluation of the environmental impact of agriculture at the farm level: a comparison and analysis of 12 indicator-based methods. Agriculture, Ecosystems \& Environment, 93, 131-145.

VAN DER WERF, H. M. \& SALOU, T., 2015. Economic value as a functional unit for environmental labelling of food and other consumer products. Journal of Cleaner Production, 94, 394-397.

VITOUSEK, P. M., ABER, J. D., HOWARTH, R. W., LIKENS, G. E., MATSON, P. A., SCHINDLER, D. W., SCHLESINGER, W. H. \& TILMAN, D. G., 1997. Human alteration of the global nitrogen cycle: sources and consequences. Ecological Applications, 7, 737-750.

WACKERNAGEL, M. \& REES, W. E., 1997. Perceptual and structural barriers to investing in natural capital: economics from an ecological footprint perspective. Ecological Economics, 20, 3-24.

WCED (WORLD COMMISSION ON ENVIRONMENT AND DEVELOPMENT), 1987. Our Common Future. Oxford, Oxford University Press.

ZHANG, W., RICKETTS, T. H., KREMEN, C., CARNEY, K. \& SWINTON, S. M., 2007. Ecosystem services and dis-services to agriculture. Ecological Economics, 64, 253-260. 